\title{
Placental aging and oxidation damage in a tissue micro-array model: an immunohistochemistry study
}

\author{
Ambrogio P. Londero ${ }^{1,2} \cdot$ Maria Orsaria $^{3} \cdot$ Stefania Marzinotto $^{3} \cdot$ Tiziana Grassi $^{1}$ • \\ Arrigo Fruscalzo $^{4,5} \cdot$ Angelo Calcagno $^{1} \cdot$ Serena Bertozzi $^{6} \cdot$ Nastassia Nardini $^{3}$. \\ Enrica Stella ${ }^{1}$ Ralph J. Lellé ${ }^{5}$ Lorenza Driul ${ }^{1} \cdot$ Gianluca Tell $^{3} \cdot$ Laura Mariuzzi $^{3}$
}

Accepted: 11 April 2016

(C) Springer-Verlag Berlin Heidelberg 2016

\begin{abstract}
To evaluate the expression of markers correlated with cellular senescence and DNA damage (8-hydroxy-2'-deoxy-guanosine (8-OHdG), p53, p21, APE1/Ref-1 (APE1), interleukin (IL-6 and IL-8) in placentas from healthy and pathologic pregnancies. This retrospective study considered a placental tissue micro-array containing 92 controls from different gestational ages and 158 pathological cases including preeclampsia (PE), HELLP syndrome (hemolysis, elevated liver enzymes, low platelet count), small for gestational age (SGA) fetuses, and intrauterine growth restriction (IUGR) occurring at different gestational ages. In this study, we demonstrated a significant influence of gestational age on the
\end{abstract}

Electronic supplementary material The online version of this article (doi:10.1007/s00418-016-1435-6) contains supplementary material, which is available to authorized users.

Ambrogio P. Londero

ambrogio.londero@gmail.com

1 Clinic of Obstetrics and Gynecology, Deparment of Experimental Clinical and Medical Science, University of Udine, Piazzale SM della Misericordia, 15, 33100 Udine, Italy

2 Unit of Obstetrics and Gynecology, S. Polo Hospital, 34074 Monfalcone, GO, Italy

3 Department of Medical and Biological Sciences, University of Udine, 33100 Udine, Italy

4 Frauenklinik, St Franziskus Hospital, Münster, Germany

5 Clinic of Obstetrics and Gynecology and Institute of Pathology, University Hospital of Münster, Albert-Schweitzer-Campus 1, Gebäude: A1, 48149 Münster, Germany

6 Department of Surgical Oncology, IRCCS CRO, 33081 Aviano, PN, Italy expression in the trophoblast of 8-OHdG, p53, p21, APE1, and IL-6. In placentas of cases affected by PE, HELLP, or IUGR, there was an increased expression of $8-\mathrm{OHdG}$, p53, APE1, and IL-6 compared to controls (only IL-8 was significantly decreased in cases). In both groups of pathology between 22- and 34-week gestation and after 34-week gestation, APE1 levels were higher in the trophoblast of women affected by hypertensive disorders of pregnancy than women carrying an IUGR fetus. The cytoplasmic expression of 8-OHdG was increased in placentas in IUGR cases compared to PE or HELLP pregnancies. In cases after 34-week gestation, p21 was higher in SGA and IUGR than in controls and late PE. Moreover, p53 was increased after 34-week gestation in IUGR pregnancies. Placentas from pathological pregnancies had an altered expression of 8-OHdG, p53, p21, APE1, IL-6, and IL-8. The alterations of intracellular pathways involving these elements may be the cause or the consequence of placental dysfunction, but in any case reflect an impaired placental function, possibly due to increased aging velocity in pathologic cases.

Keywords 8 -OHdG $\cdot$ p53 p21 - APE1/Ref- $1 \cdot$ IL-6 $~ \cdot$ IL$8 \cdot$ Placenta $\cdot$ Preeclampsia $\cdot$ IUGR

$\begin{array}{ll}\text { Abbreviations } \\ \text { 8-OHdG } & \text { 8-Hydroxy-2'-deoxy-guanosine } \\ \text { AP } & \text { Apurinic/apyrimidinic } \\ \text { APE1 } & \begin{array}{l}\text { APE1/Ref-1 (apurinic apyrimidinic endonucle- } \\ \text { ase redox effector factor-1) }\end{array} \\ \text { BER } & \begin{array}{l}\text { Base excision repair } \\ \text { Body mass index }\end{array} \\ \text { BMI } & \begin{array}{l}\text { Deoxyribonucleic acid } \\ \text { DNA }\end{array} \\ \text { HELLP } & \begin{array}{l}\text { Hemolysis, elevated liver enzymes, low platelet } \\ \text { count }\end{array} \\ \text { IL-6 } & \text { Interleukin-6 }\end{array}$




$\begin{array}{ll}\text { IL-8 } & \text { Interleukin-8 } \\ \text { IUGR } & \text { Intrauterine growth restriction } \\ \text { mRNA } & \text { Messenger ribonucleic acid } \\ \text { PE } & \text { Preeclampsia } \\ \text { RNA } & \text { Ribonucleic acid } \\ \text { SASP } & \text { Senescence-associated secretory phenotype } \\ \text { SGA } & \text { Small for gestational age }\end{array}$

\section{Introduction}

Cell senescence is part of the life cycle of all living organisms. The placenta is no exception: It too is formed, grows, performs its multiple functions (e.g., endocrine regulation and nourishment of the fetus), and ages. Of course, it is clear to us that a placenta's life cycle lasts the course of a pregnancy just as it is clear that the speed of aging varies from individual to individual. In the same way, some individuals age more quickly than others, so there are likely to be some placentas that show signs of aging faster than others.

Cell aging may lead to apoptosis, resulting in aging first of tissues and subsequently organs. The placenta is an organ that may be related to several diseases: preeclampsia (PE), HELLP syndrome (hemolysis, elevated liver enzymes, low platelet count), gestational hypertension (GH), intrauterine growth restriction (IUGR), and small for gestational age (SGA) fetus. In addition, recent studies suggest that cell senescence may play a role in PE and IUGR (Biron-Shental et al. 2010; Kudo et al. 2000; Izutsu et al. 1998; Davy et al. 2009).

Cellular senescence is the result of progressive DNA damage (Lombard et al. 2005) which is responsible for the development of the cell's senescent phenotype and it is determined by intrinsic (or endogenous) or extrinsic (exogenous) causes. Among intrinsic factors, the reactive oxygen metabolites are the most frequent cause of damage. We evaluated the tissue immunohistochemical expression of a marker that highlights the presence of oxidized DNA: 8-hydroxy2 -deoxy-guanosine $(8-\mathrm{OHdG})$. DNA damage results in the activation of tumor suppressor genes such as p53, which, in turn, lead to apoptosis and cell senescence, resulting in the loss of proliferative capacity (Rossi et al. 2008).

The p53 protein is a central transcription factor in the DNA damage response cascade. The $\mathrm{p} 53$ protein has many functions including transcription regulation, mRNA translation inhibition, DNA exonuclease, and genomic damage detection and repair (Ginsberg et al. 1991; Ewen and Miller 1996; Reed et al. 1995). Once activated, p53 exerts its function in different ways: stimulation of transcription of genes involved in apoptosis, thus activating the apoptotic cascade (Miyashita et al. 1995; Rossé et al. 1998) or activation of p21 transcription to arrest the cell in the G1 phase and repair the DNA damage (Ljungman 2000). Without p21, p53 cannot stop the cycle in G1, as has been observed in mouse embryonic fibroblasts with DNA damage due to ionizing radiation ( $\mathrm{Ju}$ et al. 2007). In addition to $\mathrm{p53}$, there are also other factors (growth factors, cytokines, or glucocorticoids) that positively regulate $\mathrm{p} 21$ levels.

Damage caused by oxidative stress, including changes to DNA and proteins, as well as the mechanisms of DNA repair, appears to play a key role in obstetrical pathologies of placental origin, including PE and IUGR (Vascotto et al. 2007; Takagi et al. 2004; Kimura et al. 2013; Rossi et al. 2013; Tamura et al. 2011). In this paper, we also focus our attention on the immunohistochemical expression of APE1/ Ref-1 (APE1). This is involved both in the base excision repair (BER) pathway of DNA lesions, acting as the major apurinic/apyrimidinic (AP) endonuclease, and in transcriptional regulation of gene expression, where it functions as a redox co-activator of different transcription factors that could lead to increased interleukin (IL)- 6 and IL-8 expression (Cesaratto et al. 2013; Thakur et al. 2015; Tell et al. 2005). IL-6 and IL-8 are two important immune-modulatory cytokines that are part of the senescence-associated secretory phenotype (SASP) (Coppé et al. 2008). SASP components could regulate the extracellular environment through both autocrine and paracrine mechanisms and chemokine or inflammatory cytokine signals are crucial senescence regulators (Young and Narita 2009). In particular, IL-6 has a central role in maintaining and amplifying the pro-senescence activity (Young and Narita 2009). Furthermore, APE1 also has a role in telomere maintenance that we saw to be involved in pregnancy diseases of placental origin (Madlener et al. 2013; Biron-Shental et al. 2010).

This study aims to evaluate the expression of certain proteins correlated with cellular senescence in placentas from both healthy and pathologic pregnancies. In particular, we studied expressions of the following: an oxidative stress damage marker to the DNA double strand, p53, p21, APE1, IL-6, and IL-8.

\section{Materials and methods}

\section{Clinical information}

This retrospective study was approved by the internal review board (IRB) and conducted in accordance with the Declaration of Helsinki. We considered the following pathologies: PE, HELLP, GH, SGA, and IUGR. PE, GH, and HELLP were based on previous definitions. Diagnosis of GH was defined as systolic blood pressure of $140 \mathrm{mmHg}$ or more and diastolic blood pressure of $90 \mathrm{mmHg}$ or more on two occasions after 20 weeks of gestation in a previously normotensive woman (Brown et al. 2001). PE was defined as the same as $\mathrm{GH}$, but with proteinuria that was 
considered as the urinary excretion of $0.3 \mathrm{~g}$ protein or greater in a 24-h period (this usually correlates with $30 \mathrm{mg}$ / $\mathrm{dl}$ or greater in a random urine determination) (Brown et al. 2001). HELLP was defined as the presence of hemolysis, cytolysis (elevated liver enzymes), and thrombocytopenia (platelets count $<100,000$ ) (Baxter and Weinstein 2004; Fruscalzo et al. 2012). Similarly, IUGR (estimated fetal weight $<10$ th centile and umbilical artery pulsatility index $>2$ standard deviations) and SGA fetuses (estimated fetal weight $<10$ th centile with normal fetal Doppler) were based on previous definitions (Visentin et al. 2014). Gestational age at pregnancy term was based on last menstrual period with fetal dating confirmed by ultrasound in the first trimester of gestation. Furthermore, considered pathologies were stratified according to gestational age into those diagnosed before and those diagnosed after 34 complete week gestation. Other clinical information was gathered from the local clinical database and included the following: maternal age, pre-pregnancy body mass index (BMI), parity, maternal race, fetal sex, and both neonatal and placental weight. We restricted our population to Caucasians and black Africans. Lastly, we calculated placental index by dividing placental weight in grams (placentas were weighed shortly after delivery with membranes and umbilical cord attached) by birth weight in grams (Londero et al. 2013).

\section{Markers and patients selection}

This study investigates the immunohistochemical expression of 8-OHdG, p53, p21, APE1, IL-6, and IL-8 in placental cytotrophoblast and syncytiotrophoblast. Our control set consisted of: 28 placentas from voluntary pregnancy interruption before the 12- or 22-week gestation; 13 placentas from voluntary pregnancy interruption for severe fetal malformations at the University of Muenster between the 22and 34-week gestation; and 51 placentas from deliveries found to have a normal pregnancy course. For pregnancy pathologies, our cases diagnosed before 34-week gestation comprised: 36 placentas from pregnancies affected by $\mathrm{PE} ; 8$ placentas from pregnancies affected by PE associated with IUGR; 17 placentas from pregnancies affected by IUGR; and 6 placentas from pregnancies affected by HELLP. Cases diagnosed after 34-week gestation comprised: 14 placentas from pregnancies affected by PE; 7 placentas from pregnancies affected by $\mathrm{PE}$ associated with IUGR; 18 placentas from pregnancies affected by SGA; 35 placentas from pregnancies affected by IUGR; 11 placentas from pregnancies affected by GH; 6 placentas from pregnancies affected by GH and SGA. All placentas from pathologic pregnancies were identified from the registry of the Pathology Department of the Udine University for the period from January 2001 to December 2010. The pathology set as a whole consisted of all available placentas from pregnancies diagnosed with the studied pathologies from the Pathology Institute of the University of Udine. Selection of the full-term delivery cases was on the basis of available placentas from the last 51 consecutively placed normal pregnancies from the Pathology Institute of the University of Udine; similarly, the selection for those before 12 or 22 weeks was the last 28 consecutively placed voluntary pregnancy terminations before 12- or 22-week gestation (in respect to Italian laws), all as reported in the department register of Udine (Italy). Control cases before 34-week gestation were the last 13 consecutively placed voluntary pregnancy terminations before 34-week gestation as reported in the department register of University of Muenster (Germany). These 13 normally evolved pregnancies were terminated in accordance with local law via medically induced abortion as a result of isolated fetal malformations (five Spina bifida, four hydrocephalus, and four cardiac complex malformations) and were in part used for a previous study (Fruscalzo et al. 2012). All pregnancies in our sample were singleton. Clinical information was gathered from our clinical files. We excluded pregnancies with the following characteristics: those known to be complicated by infection or placenta abruptio, those carrying a vanishing twin, those resulting in early preterm labor and subsequent delivery, and those with chromosomal abnormalities. In the control group, we additionally excluded other pathologies (gestational diabetes, pre-gestational diabetes, colestasis).

\section{Preparation of tissue micro-array}

Placental tissue blocks were fixed by formalin and included in paraffin. Sections were then stained by hematoxylineosin (H\&E), and carefully examined, excluding areas of placental infarction, before performing sampling for the tissue micro-array. We consequently obtained two biopsies for each identified paraffin block. Tissue micro-array (TMA) was completed using a Beecher tissue micro-arrayer. A cylindrical, thin-walled needle (inner diameter of $1.5 \mathrm{~mm}$ ) was used for coring tissues and for transferring cored samples into array cavities in the recipient block. From the recipient block, we obtained 4- $\mu \mathrm{m}$-thick transverse sections, which were placed on a glass slide and stained. For this study, we used six sections and all samples proved adequate for evaluation.

\section{Analysis of tissue micro-array}

Sections were deparaffinated, rehydrated, and incubated with $\mathrm{H}_{2} \mathrm{O}_{2}$ for $10 \mathrm{~min}$ to block endogenous peroxidase activity. Antigen retrieval was performed in citrate buffer at pH6 (high $\mathrm{pH}$ in case of IL-6 and IL-8) and at a temperature of $98{ }^{\circ} \mathrm{C}$. The sections were rinsed in PBS and then incubated in a wet chamber at room temperature for 
60 min with the following antibodies: p53 (Dako, diluted 1:100, monoclonal), p21 (Calbiochem, diluted 1:25, monoclonal), 8-OHdG (JaICA, diluted 1:10, monoclonal), IL-6 (Abcam, AB6672, diluted 1:400, polyclonal), IL-8 (Abcam, AB106350, diluted 1:250, polyclonal), and APE1 (Novus, diluted 1:300, monochlonal) (Vascotto et al. 2009). A Dako REAL ${ }^{\mathrm{TM}}$ EnVision $^{\mathrm{TM}}$ Dako Rabbit/Mouse (K5007, DakoCytomation, Glostrup, DK) was used as second antibody. HRP activity was detected using Dako REALTM DAB + Chromogen (K5007, DakoCytomation, Glostrup, DK) as substrate for $3 \mathrm{~min}$ in accordance with the manufacturer's instructions. Sections were counter stained with hematoxylin before mounting. To provide a negative control, we used the primary antibody without adding the secondary antibody, while a positive control was achieved by analyzing different tissue samples suggested by manufacturer. Two pathologists independently performed semiquantitative analysis of the immunohistochemical staining. Cytoplasm staining was evaluated by intensity score as strong 3 , moderate 2 , weak 1 , and absent 0 . Nuclear staining for APE1 and 8-OHdG was evaluated by $\mathrm{H}$-score (the product of actual percentage of positive-stained nuclei and intensity score-evaluated as strong 3, moderate 2 and weak 1 -giving a possible range of $0-300$ ) while, as per the standard protocol of our Institute of Pathology, nuclear expression of p21 and p53 was evaluated as percentage of positive nuclei. In case of discordance, a joint assessment was performed by the two pathologists.

\section{Statistical analysis}

Data were analyzed using $\mathrm{R}$ version 3.0.1 with $p<0.05$ considered significant. $T$ test, Wilcoxon test, Kruskal-Wallis test, Spearman test, Kendall test, Chi-square test, and Fisher exact tests were performed as appropriate. In addition, multivariate logistic regression analysis was performed, for which the expression of a marker over the median of its distribution was considered as the dependent variable.

\section{Results}

\section{Population description}

In Table 1, we report the general characteristics of the study population. Table 1A summarizes the characteristics of pathological and healthy pregnancies before 34-week gestation, where we note a significantly reduced placental weight in IUGR cases.

Table 1B reports the characteristics of pathological and healthy pregnancies after 34-week gestation. As expected, significant differences have been found for maternal age,
BMI before pregnancy, gestational age at the end of pregnancy, neonatal weight, nulliparity, and race.

Immunohistochemical analysis of 8-OHdG, p53, p21, APE1, IL-6, and IL-8 in the normal placenta

We observed p53 and p21 expressions only in the nucleus, IL-6 and IL-8 expressions only in the cytoplasm, and APE1 and 8-OHdG expressions in both the nucleus and the cytoplasm. Figure 1, taking into consideration only control placentas, shows the immunohistochemical expression of the studied proteins correlated with gestational age. P21 was found to significantly decrease as gestational age increased. Looking solely at controls, p53 and IL-6 levels seemed constant with increasing gestational age. As gestational age increased, so too did APE1 and 8-OHdG immunohistochemical expressions into the nuclei, while in the cytoplasm only APE1 increased with gestational age, with 8-OHdG decreasing $(p<0.05)$ (Fig. 1). In addition, we found a non-significant increase of IL- 6 and decrease of IL-8 with the increase in gestational age (Fig. 1g, h).

Although both p53 and p21 immunohistochemical scores showed a significant positive correlation $(p<0.05)$, the immunohistochemical score for p21 was higher than that of p53. In fact, Table 2 shows that in control placentas, both between 22- and 34-week gestation and after 34-week gestation, p21 expression was three to ten times higher than p53. Furthermore, if we took only controls, or both controls and cases together or stratified by gestational age, nuclear 8-OHdG score was significantly and positively correlated with nuclear p53 and nuclear APE1 scores $(p<0.05)$. In addition, nuclear APE1 was positively correlated with cytoplasmic IL-6 score and nuclear p53 score $(p<0.05)$.

We then proceeded to assess whether correlations existed between the expression of the studied factors and the placental index. Interestingly, we discovered a significant positive correlation between placental index and 8-OHdG immunohistochemical score in control placentas $(p<0.05)$, while in pathological placentas the correlation with 8-OHdG lost its significance.

\section{Immunohistochemical analysis of 8-OHdG, p53, p21, APE1, IL-6, and IL-8 in pregnancy pathology before 34-week gestation and in controls}

Table 2A reports immunohistochemical expression of the studied proteins among the various pathology groups and controls with pregnancies terminated before 34 -week gestation, and from these data we can assess the differences between cases and controls. The most prominent differences are to be seen in the expressions of $8-\mathrm{OHdG}, \mathrm{p} 53$, 
Table 1 Description of the population: (A) cases and controls <34-week gestation; (B) cases and controls $>34$-week gestation

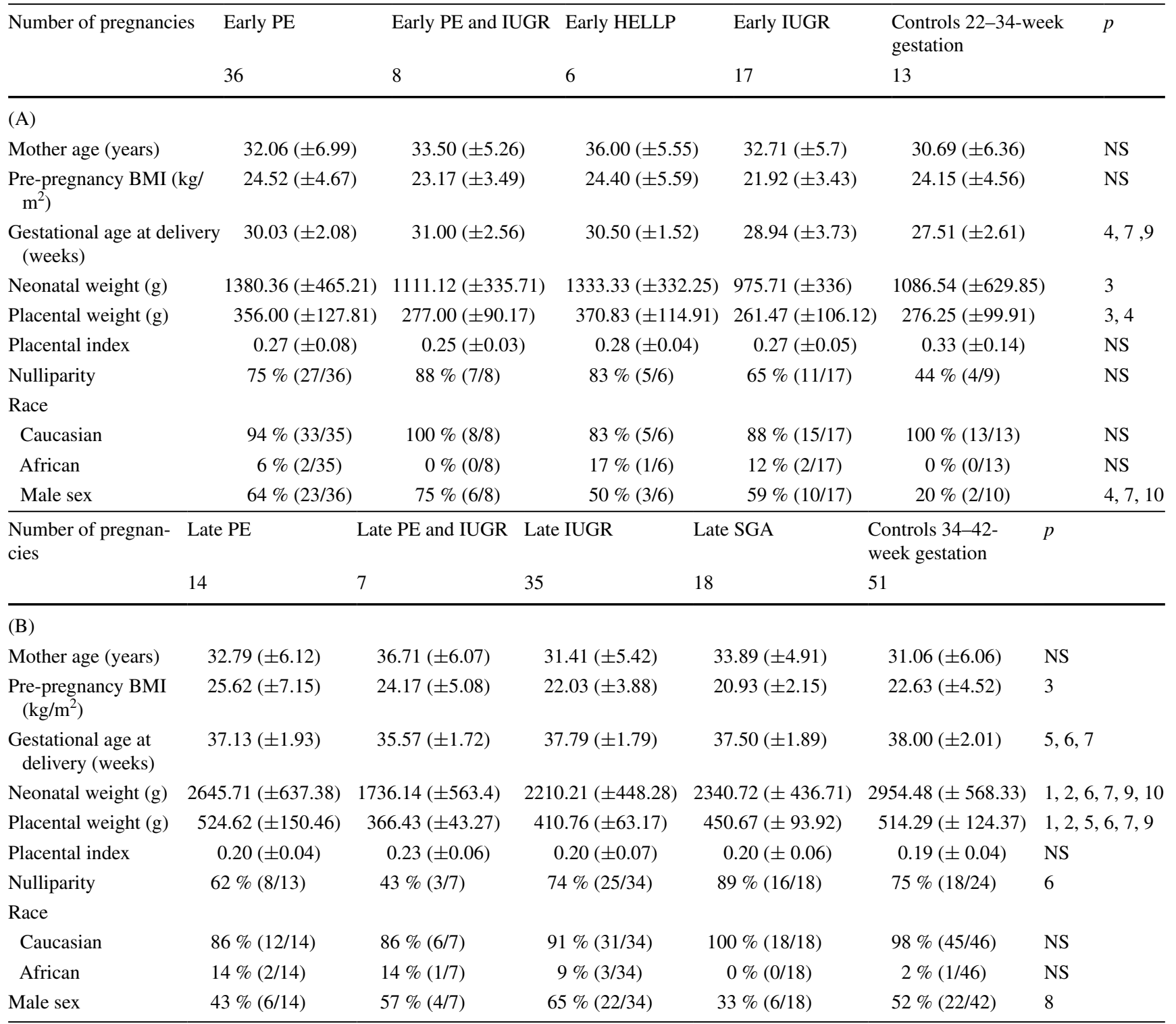

The values reported refer to mean \pm standard deviation or percentage and absolute values, and $p$ values refer to $t$ test, Chi-square test of Fisher exact test

(A) Significant differences between: (1) early PE versus early PE and IUGR; (2) early PE versus early HELLP; (3) early PE versus early IUGR; (4) early PE versus controls 22-34-week gestation; (5) early PE and IUGR versus early HELLP; (6) early PE and IUGR versus early IUGR; (7) early PE and IUGR versus controls 22-34-week gestation; (8) early HELLP versus early IUGR; (9) early HELLP versus controls 22-34-week gestation; (10) early IUGR versus controls 22-34-week gestation. (Ns) = non-significant

(B) Significant differences between: (1) late PE versus late PE and IUGR; (2) late PE versus late IUGR; (3) late PE versus late SGA; (4) late PE versus controls 34-42-week gestation; (5) late PE and IUGR versus late IUGR; (6) late PE and IUGR versus late SGA; (7) late PE and IUGR versus controls 34-42-week gestation; (8) late IUGR versus Late SGA; (9) late IUGR versus controls 34-42-week gestation; (10) late SGA versus controls 34-42-week gestation. (NS) = non-significant

APE1, IL-6, and IL-8 (Tables 2A, 3). In fact, nuclear $\mathrm{H}$-score of 8-OHdG, p53 positivity, cytoplasmatic intensity of APE1, and IL-6 were all found to be higher in every pathology group than in controls (Fig. 2). Nuclear $\mathrm{H}$-score of APE1 was significantly increased only in PE or HELLP cases when compared with controls (Fig. 2) and cytoplasmic intensity score of IL-8 was significantly decreased in every pathology group in comparison with controls (Table 3).

Looking at variations between the pathology groups in more depth, we observed that nuclear APE1 expression levels were higher in PE and HELLP pregnancies than 


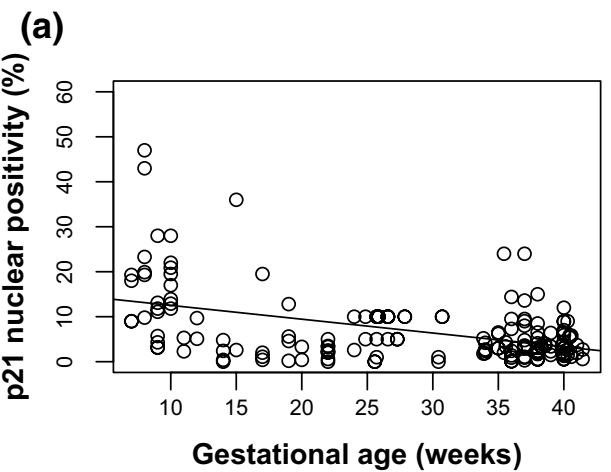

(c)

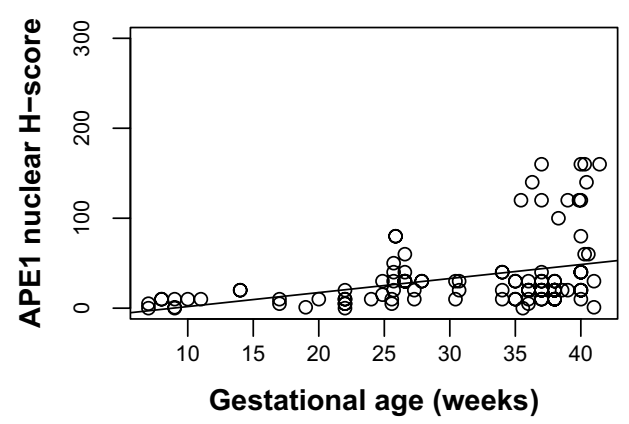

(e)

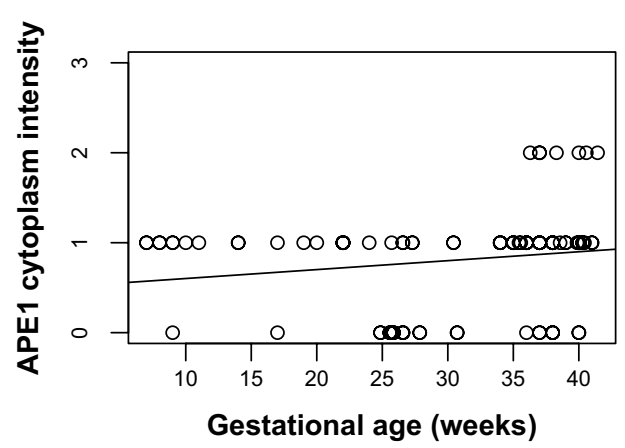

(g)

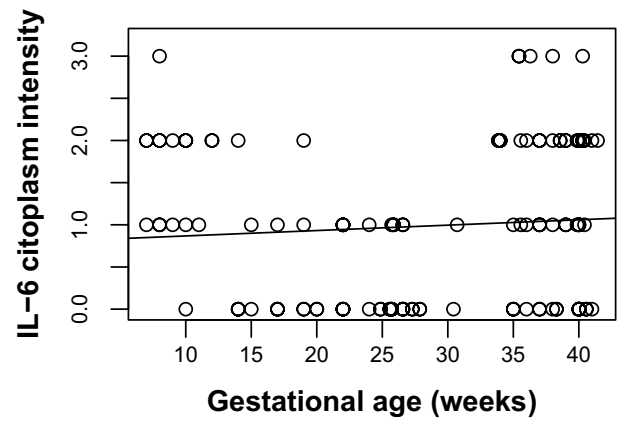

Fig. 1 Correlation between gestational age and expression of studied proteins. a p21 nuclear positivity Spearman's rho $=-0.350$ $(p<0.05$, Kendall's $p<0.05)$. b p53 nuclear positivity Spearman's rho $=0.056(p=0.477$, Kendall's $p=0.493)$. c: APE1 nuclear positivity Spearman's rho $=0.418(p<0.05$, Kendall's $p<0.05)$. d 8 -OHdG nuclear positivity Spearman's rho $=0.655(p<0.05$, Ken- (b)

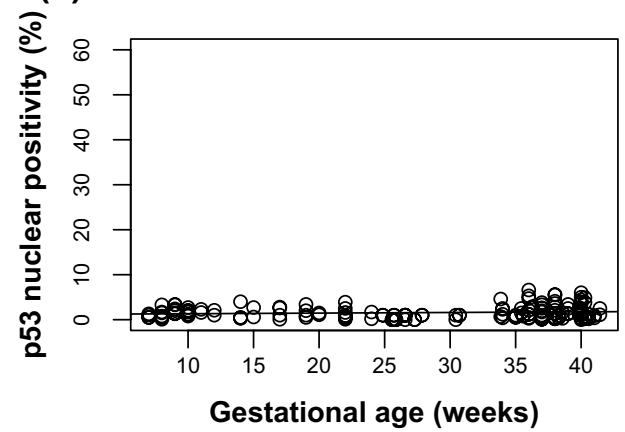

(d)

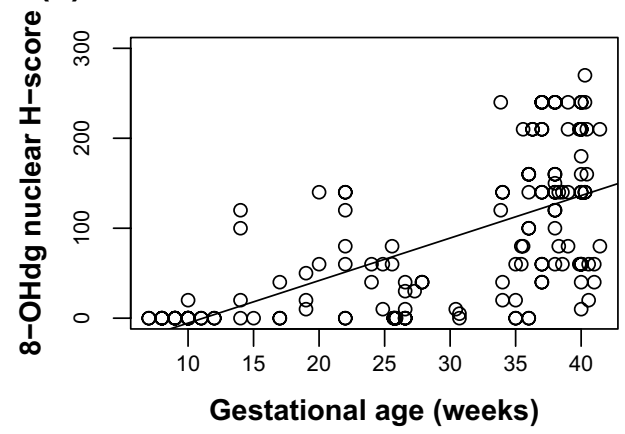

(f)

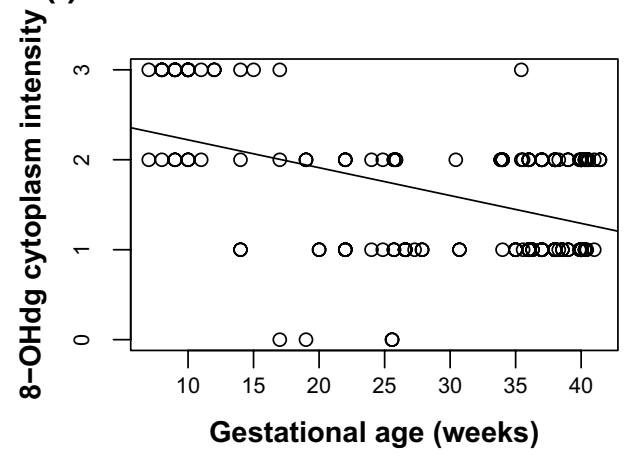

(h)

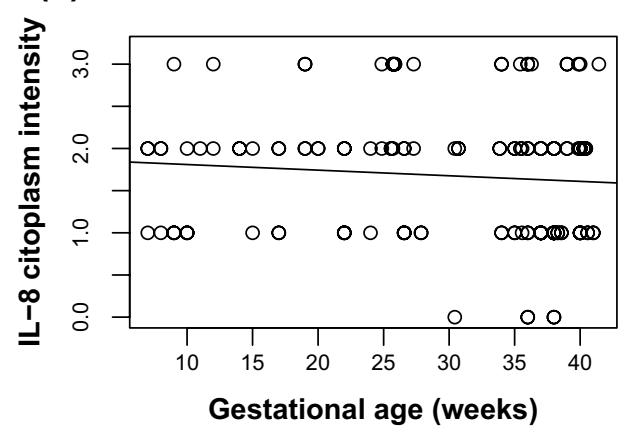

dall's $p<0.05)$. e APE1 cytoplasm intensity Spearman's rho $=0.230$ $(p<0.05$, Kendall's $p<0.05)$. f 8-OHdG cytoplasm intensity Spearman's rho $=-0.322(p<0.05$, Kendall's $p<0.05)$. g IL-6 cytoplasm intensity Spearman's rho $=0.099(p=0.267$, Kendall's $p=0.298)$. h IL-8 cytoplasm intensity Spearman's rho $=-0.102(p=0.215$, Kendall's $p=0.247$ ) 
Table 2 Immunohistochemical expression of 8-OHdG, p53, p21, APE1, IL-6, and IL-8 in: (A) early and (B) late pathology of pregnancy

$\begin{array}{lllll}\text { Early PE } & \text { Early PE and IUGR Early HELLP } & \text { Early IUGR } & \begin{array}{l}\text { Controls 22-34- } \\ \text { week gestation }\end{array} & p\end{array}$

\begin{tabular}{|c|c|c|c|c|c|c|}
\hline \multicolumn{7}{|l|}{ (A) } \\
\hline $\begin{array}{l}\text { Nuclear positivity of } \\
\text { p21 }\end{array}$ & $7.3(3.5-14.8)$ & $5.1(2.5-15.2)$ & $6.5(1.5-11.0)$ & $6.9(4.6-10.9)$ & $10.0(5.0-10.0)$ & NS \\
\hline $\begin{array}{l}\text { Nuclear positivity of } \\
\text { p53 }\end{array}$ & $1.4(0.6-2.5)$ & $1.2(0.6-1.7)$ & $2.0(0.4-4.2)$ & $1.2(0.7-2.0)$ & $1.0(0.0-1.0)$ & $4,7,9,10$ \\
\hline $\begin{array}{l}\text { Nuclear H-score of } \\
\text { APE1 }\end{array}$ & $40.0(20.0-100.0)$ & $25.0(12.5-67.5)$ & $70.0(30.0-100.0)$ & $30.0(10.0-40.0)$ & $30.0(20.0-32.5)$ & $3,4,9$ \\
\hline $\begin{array}{l}\text { Cytoplasm intensity of } \\
\text { APE1 }\end{array}$ & f1.0 (1.0-1.0) & $1.0(1.0-1.0)$ & $1.0(1.0-1.0)$ & $1.0(1.0-1.0)$ & $0.0(0.0-1.0)$ & $1,3,4,7,9,10$ \\
\hline $\begin{array}{l}\text { Nuclear H-score } \\
\text { 8-OHdG }\end{array}$ & $140.0(10.0-160.0)$ & $90.0(40.0-187.5)$ & $130.0(10.0-172.5)$ & $90.0(25.0-155.0)$ & $10.0(0.0-40.0)$ & $4,7,9,10$ \\
\hline $\begin{array}{l}\text { Cytoplasm intensity of } \\
\text { 8-OHdG }\end{array}$ & f $1.0(1.0-2.0)$ & $1.5(1.0-2.0)$ & $1.0(0.8-1.2)$ & $2.0(1.0-2.0)$ & $1.0(1.0-2.0)$ & 8 \\
\hline $\begin{array}{l}\text { Cytoplasm intensity } \\
\text { of IL-6 }\end{array}$ & $1.0(0.0-2.0)$ & $2.0(1.0-2.0)$ & $1.0(0.0-2.0)$ & $1.0(0.0-2.0)$ & $0.0(0.0-1.0)$ & $4,7,10$ \\
\hline \multirow{2}{*}{$\begin{array}{l}\text { Cytoplasm intensity } \\
\text { of IL-8 }\end{array}$} & $1.0(1.0-1.0)$ & $1.0(1.0-1.0)$ & $1.0(1.0-1.0)$ & $1.0(1.0-2.0)$ & $2.0(1.2-2.8)$ & $4,7,9,10$ \\
\hline & Late PE & Late PE and IUGR & Late IUGR & Late SGA & $\begin{array}{l}\text { Controls 34-42- } \\
\text { week gestation }\end{array}$ & $p$ \\
\hline \multicolumn{7}{|l|}{ (B) } \\
\hline $\begin{array}{l}\text { Nuclear positivity of } \\
\text { p21 }\end{array}$ & $2.5(1.6-5.2)$ & $9.0(3.0-13.3)$ & $5.0(3.0-12.1)$ & $5.6(2.9-8.7)$ & $3.1(1.8-5.9)$ & $1,2,3,7,9,10$ \\
\hline $\begin{array}{l}\text { Nuclear positivity of } \\
\text { p53 }\end{array}$ & $1.5(0.7-2.0)$ & $2.5(2.0-3.2)$ & $2.0(1.3-2.9)$ & $2.2(0.9-3.0)$ & $1.4(0.6-2.6)$ & $1,2,7,9$ \\
\hline $\begin{array}{l}\text { Nuclear H-score of } \\
\text { APE1 }\end{array}$ & $50.0(27.5-85.0)$ & $75.0(45.0-130.0)$ & $20.0(10.0-30.0)$ & $20.0(10.0-30.0)$ & $20.0(20.0-70.0)$ & $2,3,5,6,7,9$ \\
\hline $\begin{array}{l}\text { Cytoplasm intensity of } \\
\text { APE1 }\end{array}$ & f $1.0(1.0-1.2)$ & $1.0(1.0-1.0)$ & $1.0(1.0-1.0)$ & $1.0(1.0-1.0)$ & $1.0(1.0-1.0)$ & $2,3,4$ \\
\hline $\begin{array}{l}\text { Nuclear H-score } \\
\text { 8-OHdG }\end{array}$ & $120.0(60.0-150.0)$ & $135.0(90.0-197.5)$ & $80.0(40.0-160.0)$ & $160.0(60.0-225.0)$ & $140.0(60.0-210.0)$ & 9 \\
\hline $\begin{array}{l}\text { Cytoplasm intensity of } \\
\text { 8-OHdG }\end{array}$ & f $1.0(1.0-2.0)$ & $1.5(1.0-2.0)$ & $1.0(1.0-2.0)$ & $1.0(1.0-1.0)$ & $1.0(1.0-2.0)$ & $6,8,10$ \\
\hline $\begin{array}{l}\text { Cytoplasm intensity } \\
\text { of IL-6 }\end{array}$ & $1.0(0.0-2.0)$ & $2.0(1.0-2.0)$ & $2.0(0.2-2.0)$ & $0.0(0.0-2.0)$ & $1.0(0.0-2.0)$ & 2 \\
\hline $\begin{array}{l}\text { Cytoplasm intensity } \\
\text { of IL-8 }\end{array}$ & $1.0(1.0-1.0)$ & $1.5(1.0-2.0)$ & $2.0(1.0-2.0)$ & $1.0(1.0-2.0)$ & $2.0(1.0-2.0)$ & $1,2,4,10$ \\
\hline
\end{tabular}

The values reported refers to median and interquartile range (IQR), and $p$ values refers to Wilcoxon test

(A) Significant differences between: (1) early PE versus early PE and IUGR; (2) early PE versus early HELLP; (3) early PE versus early IUGR; (4) early PE versus controls 22-34-week gestation; (5) early PE and IUGR versus early HELLP; (6) early PE and IUGR versus Early IUGR; (7) early PE and IUGR versus controls 22-34-week gestation; (8) Early HELLP versus early IUGR; (9) early HELLP versus controls 22-34-week gestation; (10) early IUGR versus controls 22-34-week gestation. (NS) = non-significant

(B) Significant differences between: (1) Late PE versus late PE and IUGR; (2) late PE versus late IUGR; (3) late PE versus late SGA; (4) late PE versus controls 34-42-week gestation; (5) late PE and IUGR versus Late IUGR; (6) late PE and IUGR versus late SGA; (7) late PE and IUGR versus Controls 34-42-week gestation; (8) late IUGR versus late SGA; (9) late IUGR versus controls 34-42-week gestation; (10) late SGA versus controls 34-42-week gestation. (NS) = non-significant

in IUGR pregnancies. Conversely, no significant differences existed when we looked at the nuclear expression of 8 -OHdG, which generally was present at higher levels in pathological than in healthy placentas, yet cytoplasmic 8-OHdG was expressed in higher levels in IUGR cases than in HELLP or PE $(p=0.071$ and $p<0.05$ selecting only HELLP). In Table 2, we found significant variations in cytoplasmic expression of APE1 without macroscopic differences among medians, and as a consequence we inspected the percentage of samples with cytoplasmatic APE1 expression. This informed us that cytoplasmic expression of APE1 was present in just $29 \%$ of control 
Table 3 Univariate and multivariate logistic regression analysis of immunohistochemical expression differences in studied proteins between controls and cases before the 34-week gestation

\begin{tabular}{|c|c|c|c|c|}
\hline & OR (IC $95 \%)$ & $p$ & OR (IC $95 \%)(*)$ & $p(*)$ \\
\hline Nuclear positivity of p21 & \multicolumn{4}{|l|}{ No significant differences in comparison with controls } \\
\hline \multicolumn{5}{|l|}{ Nuclear positivity of p53 } \\
\hline Controls 22-34-week gestation & Reference & 1.000 & Reference & 1.000 \\
\hline Early PE & $37.07(4.76-288.78)$ & $<0.05$ & $29.47(3.73-232.81)$ & $<0.05$ \\
\hline Early PE and IUGR & $41.67(4.44-391.33)$ & $<0.05$ & $29.12(3.02-280.84)$ & $<0.05$ \\
\hline Early HELLP & $35(3.49-350.59)$ & $<0.05$ & $25.98(2.55-264.96)$ & $<0.05$ \\
\hline Early IUGR & $35.71(4.32-295.06)$ & $<0.05$ & $32.97(3.92-277.43)$ & $<0.05$ \\
\hline \multicolumn{5}{|l|}{ Nuclear H-score of APE1 } \\
\hline Controls 22-34-week gestation & Reference & 1.000 & Reference & 1.000 \\
\hline Early PE & $3.8(1.34-10.76)$ & $<0.05$ & $3.93(1.28-12.11)$ & $<0.05$ \\
\hline Early PE and IUGR & $1.67(0.4-6.97)$ & 0.484 & $1.73(0.38-7.92)$ & 0.477 \\
\hline Early HELLP & $8(1.59-40.3)$ & $<0.05$ & $8.31(1.54-44.86)$ & $<0.05$ \\
\hline Early IUGR & $1.29(0.38-4.31)$ & 0.684 & $1.31(0.38-4.52)$ & 0.667 \\
\hline \multicolumn{5}{|l|}{ Cytoplasm intensity of APE1 } \\
\hline Controls 22-34-week gestation & Reference & 1.000 & Reference & 1.000 \\
\hline Early PE & $160.29(18.46-1391.75)$ & $<0.05$ & $200.25(20.44-1962.13)$ & $<0.05$ \\
\hline Early PE and IUGR & $13.36(2.33-76.48)$ & $<0.05$ & $17.25(2.49-119.41)$ & $<0.05$ \\
\hline Early HELLP & $12.14(2.1-70.22)$ & $<0.05$ & $15.48(2.27-105.65)$ & $<0.05$ \\
\hline Early IUGR & $15.79(4-62.26)$ & $<0.05$ & $18.39(4.18-80.88)$ & $<0.05$ \\
\hline \multicolumn{5}{|l|}{ Nuclear H-score 8-OHdG } \\
\hline Controls 22-34-week gestation & Reference & 1.000 & Reference & 1.000 \\
\hline Early PE & $14.55(3.18-66.54)$ & $<0.05$ & $11.81(2.53-55.06)$ & $<0.05$ \\
\hline Early PE and IUGR & $11(1.92-63.15)$ & $<0.05$ & $7.92(1.33-47.19)$ & $<0.05$ \\
\hline Early HELLP & $22(3.36-144.17)$ & $<0.05$ & $16.91(2.52-113.27)$ & $<0.05$ \\
\hline Early IUGR & $11(2.23-54.24)$ & $<0.05$ & $10.02(2-50.36)$ & $<0.05$ \\
\hline Cytoplasm intensity of 8-OHdG & No significant differences in comparison with controls & & & \\
\hline \multicolumn{5}{|l|}{ Cytoplasm intensity of IL-6 } \\
\hline Controls 22-34-week gestation & Reference & 1.000 & Reference & 1.000 \\
\hline Early PE & $8.46(1.78-40.29)$ & $<0.05$ & $7.26(1.4-37.6)$ & $<0.05$ \\
\hline Early PE and IUGR & $14.67(2.44-88.13)$ & $<0.05$ & $12.16(1.81-81.51)$ & $<0.05$ \\
\hline Early HELLP & $5.5(0.74-40.8)$ & 0.095 & $4.51(0.54-37.42)$ & 0.163 \\
\hline Early IUGR & $9.62(1.64-56.37)$ & $<0.05$ & $8.52(1.39-52.3)$ & $<0.05$ \\
\hline \multicolumn{5}{|l|}{ Cytoplasm intensity of IL-8 } \\
\hline Controls 22-34-week gestation & Reference & 1.000 & Reference & 1.000 \\
\hline Early PE & $0.07(0.02-0.21)$ & $<0.05$ & $0.09(0.03-0.27)$ & $<0.05$ \\
\hline Early PE and IUGR & $0.07(0.01-0.34)$ & $<0.05$ & $0.09(0.02-0.49)$ & $<0.05$ \\
\hline Early HELLP & $0.02(0-0.33)$ & $<0.05$ & $0.02(0-0.44)$ & $<0.05$ \\
\hline Early IUGR & $0.19(0.06-0.58)$ & $<0.05$ & $0.21(0.07-0.66)$ & $<0.05$ \\
\hline
\end{tabular}

The immunohistochemical score of 8-OHdG, p53, p21, APE1, IL-6, and IL-8 higher than the median of the distribution was considered as a dependent variable. ${ }^{*}$ ) In multivariate analysis correction for: gestational age at birth, maternal age, nulliparity, and ethnicity

placentas, which is significantly lower than in cases: $99 \%$ in PE; $100 \%$ in HELLP; $85 \%$ in PE with IUGR; and $87 \%$ in IUGR. Finally, cytoplasmic expression of APE1 was higher in isolated PE than in IUGR $(p<0.05)$ or in PE associated with IUGR ( $p=0.067)$. With regard to HELLP, no statistically significant difference was found in comparison with IUGR.
Immunohistochemical analysis of 8-OHdG, p53, p21, APE1, IL-6, and IL-8 in pregnancy pathology after 34-week gestation and controls

We can make several observations regarding differences between cases and controls from the data in Table 2B, where we report the univariate analysis of the immunohistochemical 
Fig. 2 Immunohistochemical expression in placenta from early PE and controls of $8-\mathrm{OHdG}$ and APE1. a 8 -OHdG in early PE (original magnification $\times 200$; inset, $\times 400)$. b 8 -OHdG in controls (original magnification $\times 200$; inset, $\times 400)$. c APE1 in early $\mathrm{PE}$ (original magnification $\times 200$; inset, $\times 400)$. d APE1 in controls (original magnification $\times 200$; inset,$\times 400$ )

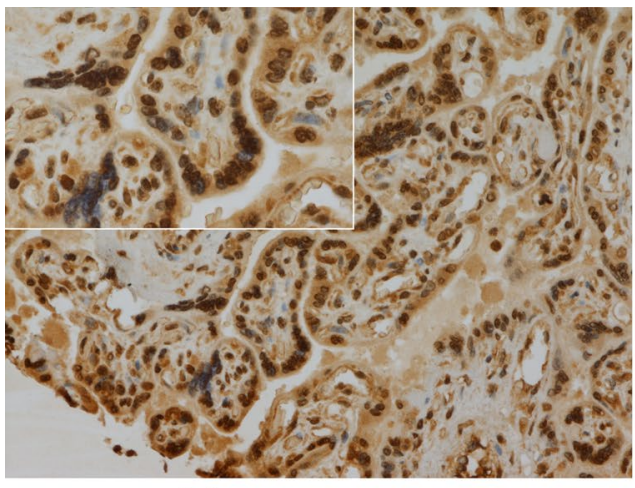

(a) Early PE - 8-OHdg.

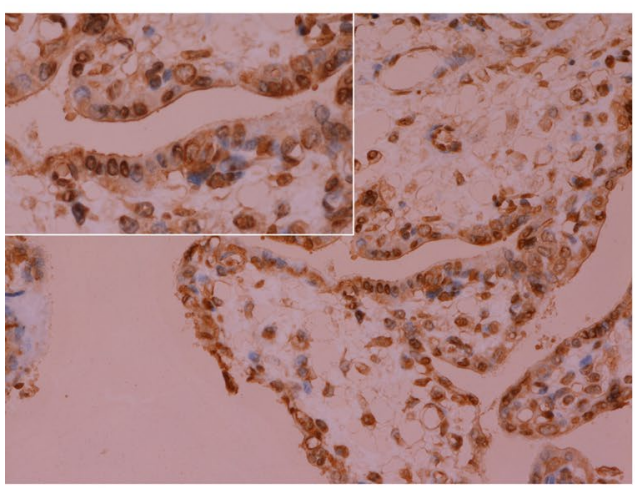

(b) Controls 22-34 weeks' gestation - 8-OHdg.

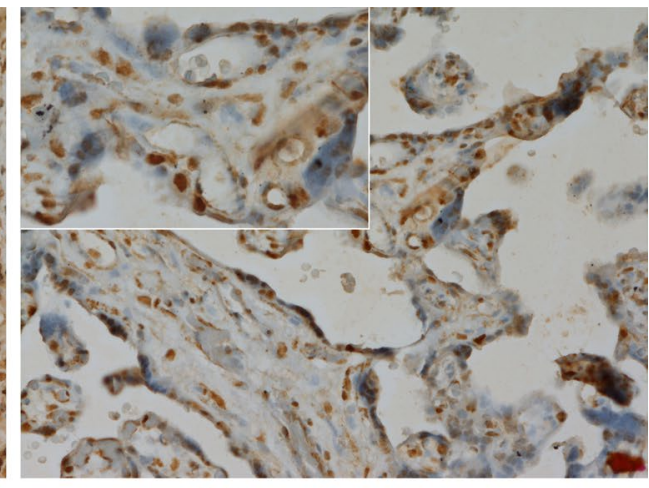

(c) Early PE - APE1.

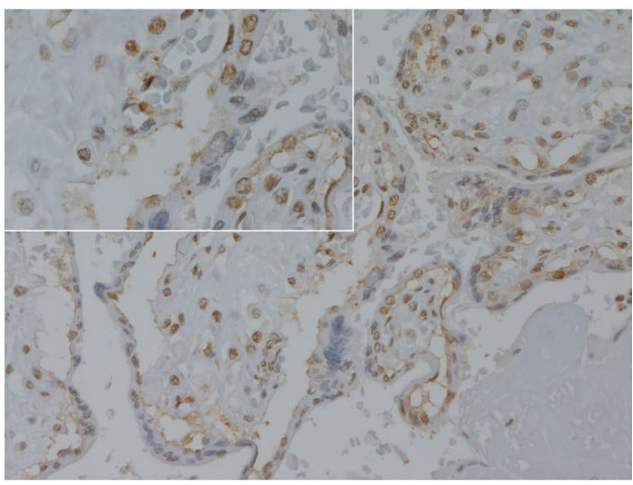

(d) Controls 22-34 weeks' gestation - APE1. expression of the studied proteins among different pathology groups and controls who delivered after 34-week gestation. We can see that in comparison with the control group, p21 expression was significantly increased in SGA and in IUGR (Tables 2B, 4; Fig. 3) and non-significantly increased in SGA associated with GH (Supplemental Table 1); p53 was significantly higher in placentas of patients affected by PE associated with IUGR than in controls (Tables 2B, 4); nuclear APE1 was significantly higher in isolated PE or PE associated with IUGR than in controls (Tables 2B, 4); and IL-6 was non-significantly increased in IUGR (Tables 2B, 4). With regard to $\mathrm{GH}$, the expression of cytoplasmic APE1 was increased compared to controls $(p=0.056)$ and IL-8 decreased $(p<0.05)$. Cases of GH with SGA presented a significantly increased expression of cytoplasmic 8-OHdG score, whereas isolated SGA had a significantly decreased expression $(p<0.05)$.

Focussing once again on differences among the pathology groups, we observed that $\mathrm{p} 21$ was significantly higher both in isolated IUGR and IUGR associated with PE than in PE alone $(p<0.05)$ (Fig. 3). A similar pattern was observed for p51: Expression of this protein was higher in IUGR than in isolated PE. Moreover, placentas affected by PE or GH presented a lower expression of p21 in comparison with SGA cases. Nuclear APE1 was found to be higher in PE than in controls $(p<0.05)$, and significantly increased in both isolated PE and PE associated with IUGR than in IUGR or SGA pregnancies $(p<0.05)$. In PE pregnancies, cytoplasmic APE1 was also higher than in SGA and IUGR pregnancies $(p<0.05)$. Cytoplasmic 8 -OHdG was higher in IUGR cases than in SGA $(p<0.05)$, while nuclear 8-OHdG was lower $(p=0.076)$. In the placentas of patients affected by isolated GH or isolated SGA compared to placentas of patients affected by $\mathrm{GH}$ in combination with SGA, 8-OHdG was increased in the nucleus $(p<0.05)$ but decreased in the cytoplasm $(p<0.05)$. Finally, IL-6 was higher in IUGR than in PE and IL-8 was higher in IUGR associated with PE than in PE alone $(p<0.05)$.

\section{Discussion}

In this study, we began by demonstrating that gestational age exerted a significant influence on the immunohistochemical expression of $8-\mathrm{OHdG}, \mathrm{p} 21$, and APE1 in the trophoblast. We then presented results that described increased expression of 8-OHdG, p53, APE1, and IL-6 in the placentas of PE, HELLP, or IUGR pregnancies when compared to controls. In pathology cases both between 22and 34-week gestation and after 34-week gestation, APE1 expression was higher in the trophoblast of patients with hypertensive disorders of pregnancy than in patients with 
Table 4 Univariate and multivariate logistic regression analysis of immunohistochemical expression differences in studied proteins between controls and cases after 34-week gestation

\begin{tabular}{|c|c|c|c|c|}
\hline & OR (IC $95 \%$ ) & $p$ & OR (IC $95 \%)(*)$ & $p(*)$ \\
\hline \multicolumn{5}{|l|}{ Nuclear positivity of p21 } \\
\hline Controls >34-week gestation & Reference & 1.000 & Reference & 1.000 \\
\hline Late PE & $0.99(0.41-2.38)$ & 0.983 & $0.91(0.37-2.26)$ & 0.840 \\
\hline Late PE and IUGR & $2.69(0.82-8.83)$ & 0.102 & $1.99(0.56-6.99)$ & 0.286 \\
\hline SGA > 34-week gestation & $2.85(1.29-6.31)$ & $<0.05$ & $2.75(1.21-6.27)$ & $<0.05$ \\
\hline Late IUGR & $2.72(1.45-5.12)$ & $<0.05$ & $2.72(1.4-5.28)$ & $<0.05$ \\
\hline \multicolumn{5}{|l|}{ Nuclear positivity of p53 } \\
\hline Controls $>34$-week gestation & Reference & 1.000 & Reference & 1.000 \\
\hline Late PE & $0.56(0.22-1.44)$ & 0.231 & $0.57(0.22-1.51)$ & 0.257 \\
\hline Late PE and IUGR & $4.21(1.23-14.36)$ & $<0.05$ & $4.27(1.18-15.51)$ & $<0.05$ \\
\hline SGA > 34-week gestation & $2(0.92-4.35)$ & 0.080 & $2.03(0.91-4.53)$ & 0.084 \\
\hline Late IUGR & $1.68(0.9-3.14)$ & 0.101 & $1.71(0.89-3.28)$ & 0.106 \\
\hline \multicolumn{5}{|l|}{ Nuclear H-score of APE1 } \\
\hline Controls $>34$-week gestation & Reference & 1.000 & Reference & 1.000 \\
\hline Late PE & $3.08(1.1-8.62)$ & $<0.05$ & $4.09(1.41-11.89)$ & $<0.05$ \\
\hline Late PE and IUGR & $5.14(1.05-25.04)$ & $<0.05$ & $8.59(1.63-45.25)$ & $<0.05$ \\
\hline SGA > 34-week gestation & $0.54(0.22-1.32)$ & 0.175 & $0.68(0.27-1.7)$ & 0.409 \\
\hline Late IUGR & $0.48(0.23-0.97)$ & $<0.05$ & $0.56(0.27-1.17)$ & 0.125 \\
\hline Cytoplasm intensity of APE1 & No significant differences in comparison with controls & & & \\
\hline Nuclear H-score 8-OHdG & No significant differences in comparison with controls & & & \\
\hline \multicolumn{5}{|l|}{ Cytoplasm intensity of 8-OHdG } \\
\hline Controls $>34$-week gestation & Reference & 1.000 & Reference & 1.000 \\
\hline Late PE & $0.81(0.34-1.93)$ & 0.630 & $0.69(0.28-1.70)$ & 0.417 \\
\hline Late PE and IUGR & $1.34(0.44-4.12)$ & 0.604 & $0.98(0.3-3.22)$ & 0.974 \\
\hline SGA > 34-week gestation & $0.42(0.17-1.00)$ & $<0.05$ & $0.36(0.15-0.89)$ & $<0.05$ \\
\hline Late IUGR & $1.00(0.54-1.87)$ & 0.989 & $0.91(0.47-1.73)$ & 0.764 \\
\hline \multicolumn{5}{|l|}{ Cytoplasm intensity of IL-6 } \\
\hline Controls >34-week gestation & Reference & 1.000 & Reference & 1.000 \\
\hline Late PE & $0.51(0.21-1.28)$ & 0.152 & $0.57(0.22-1.5)$ & 0.256 \\
\hline Late PE and IUGR & $1.44(0.46-4.57)$ & 0.531 & $1.74(0.49-6.23)$ & 0.395 \\
\hline SGA > 34-week gestation & $0.67(0.25-1.79)$ & 0.422 & $0.76(0.26-2.17)$ & 0.605 \\
\hline Late IUGR & $1.99(0.86-4.59)$ & 0.108 & $2.22(0.91-5.44)$ & 0.081 \\
\hline \multicolumn{5}{|l|}{ Cytoplasm intensity of IL-8 } \\
\hline Controls >34-week gestation & Reference & 1.000 & Reference & 1.000 \\
\hline Late PE & $0.1(0.03-0.36)$ & $<0.05$ & $0.14(0.04-0.5)$ & $<0.05$ \\
\hline Late PE and IUGR & $0.85(0.28-2.6)$ & 0.775 & $1.48(0.45-4.89)$ & 0.524 \\
\hline SGA > 34-week gestation & $0.44(0.2-0.99)$ & $<0.05$ & $0.58(0.25-1.33)$ & 0.201 \\
\hline Late IUGR & $0.96(0.51-1.78)$ & 0.885 & $1.22(0.64-2.34)$ & 0.547 \\
\hline
\end{tabular}

The immunohistochemical score of 8-OHdG, p53, p21, APE1, IL-6, and IL-8 higher than the median of the distribution was considered as a dependent variable. (*) In multivariate analysis correction for: gestational age at birth, maternal age, nulliparity, and ethnicity

IUGR. Before 34-week gestation, the cytoplasmic expression of 8-OHdG was increased in the trophoblast of placentas affected by IUGR compared with PE or HELLP. After 34-week gestation, we observed increased expression of p21 in SGA and IUGR cases compared with both controls and PE, as well as an increased expression of p53 in IUGR.
Oxidative stress damage is a known senescence trigger and the consequent DNA damage activates the p53-p21 pathway which applies cell cycle arrest (Burton and Krizhanovsky 2014). Furthermore, oxidative stress DNA damage is known to induce APE1 for DNA repair thorough the BER pathway (Thakur et al. 2015). APE1 itself favors as a redox co-activator of transcription factors the production of IL- 6 
Fig. 3 Immunohistochemical expression in placenta from late IUGR and controls of $\mathrm{p} 21$ and p53. a The $\mathrm{p} 21$ in late IUGR (original magnification $\times 200$; inset, $\times 400)$. $b$ The $\mathrm{p} 21$ in controls (original magnification $\times 200$; inset, $\times 400$ ). $\mathbf{c}$ The p53 in late IUGR (original magnification $\times 200$; inset, $\times 400$ ). $\mathbf{d}$ The $\mathrm{p} 53$ in controls (original magnification $\times 200$; inset, $\times 400$ )

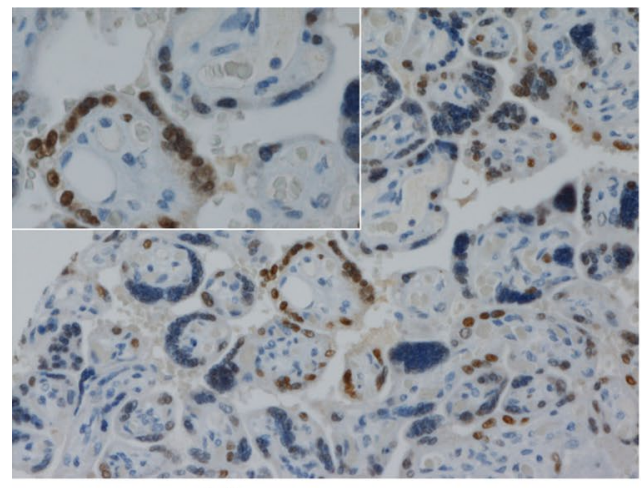

(a) Late IUGR - p21.

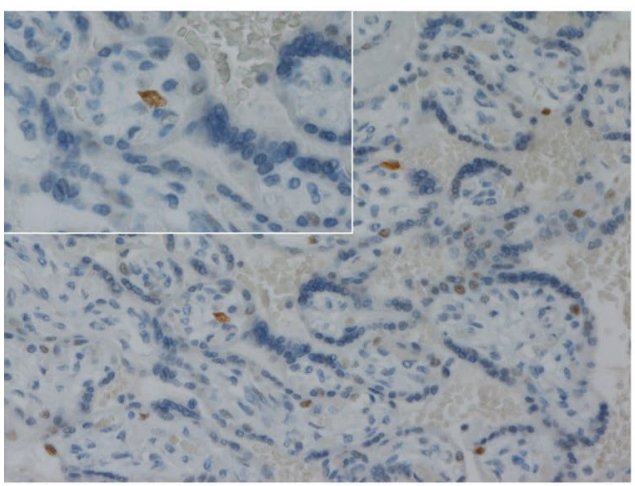

(b) Controls >34 weeks' gestation - p21.

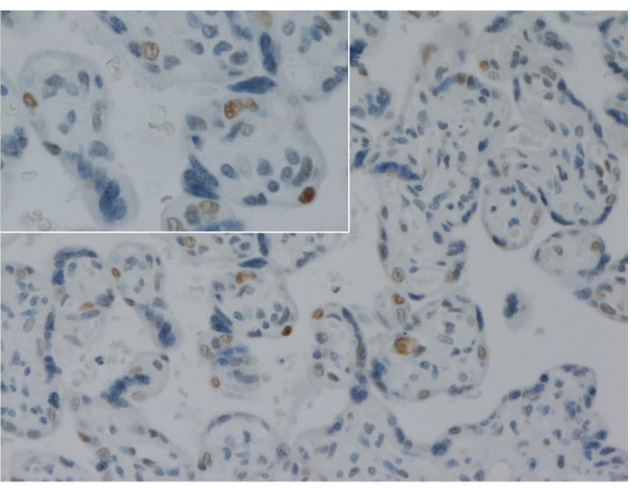

(c) Late IUGR - p53.

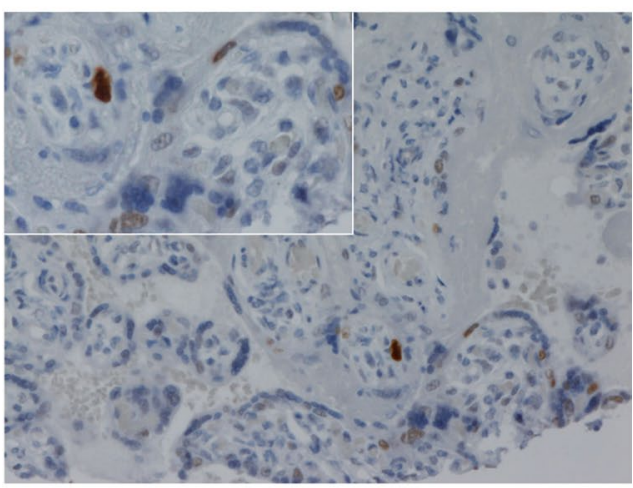

(d) Controls >34 weeks' gestation - p53. and IL-8 that are part of SASP (Coppé et al. 2008). SASP in particular could negatively impact the local microenvironment by autocrine and paracrine effects (Young and Narita 2009). In line with our expectations, our study demonstrates that as gestational age increases, so too does the immunohistochemical expression of 8-OHdG, APE1, and p53, whilecontrary to expectations- $\mathrm{p} 21$ significantly decreased with an increase in gestational age. However, our data did conclude that there was a significant positive correlation between p53 and p21 immunohistochemical scores. Therefore, these aging biomarkers in general seem to increase with placental age increase. Furthermore, considering the studied pathways in early pregnancy pathology, these biomarkers had higher immunohistochemical scores (8-OHdG, p53, APE1, and IL-6) in comparison with controls (Table 3). The only exception was the lower scores found for IL-8 in comparison with controls, and for this exception we currently do not yet have a satisfactory explanation. Looking at late pregnancy pathology, placentas from IUGR and SGA pregnancies stand out as having higher aging biomarker scores than controls (p53, p21, APE1, and IL-6) (Table 4 and Supplemental Table 1). The fact that we did not detect significance when testing for differences between 8-OHdG nuclear score in late pregnancy pathology versus controls could be attributed to a natural aging of the placenta in control cases, with the result being that they therefore present a similar pattern of DNA oxidation.
In the existing literature, there are several studies about the involvement of p21 and p53 in pregnancy pathologies related to abnormal placentation. The same can be said for APE1. IL-6 and IL-8, on the other hand, have been primarily studied in fluid samples (amniotic fluid or blood). In a review article collating findings published up to 2008 concerning the pathway of apoptosis in the trophoblast and its role in pregnancy diseases, there are conflicting results. These are in part due to the composition of the studied population and in part due to the gestational age at which the samples were collected (in most cases, gestational age is significantly different between cases and controls) (Heazell et al. 2008). The difference in gestational age between cases and controls in particular could lead to biased results because, as we found in our study, gestational age significantly influences placental protein expression.

It is known that in trophoblast isolated from pregnancies complicated by PE and IUGR there is an increased susceptibility to apoptosis (Heazell et al. 2008). These observations have informed the hypothesis that in the context of these pregnancy complications, there may be an imbalance in the regulation of apoptosis which leads to an increased susceptibility to apoptosis itself as pro-apoptotic stimuli present themselves (Heazell et al. 2008). However, although the existing literature offers plenty of evidence to indicate an increased apoptosis in the trophoblast of placentas from PE or IUGR pregnancies, there are few studies 
that investigate changes in the proteins involved in cell cycle control.

Regarding the expression of p53 in placentas from pathologic pregnancies, IUGR pregnancies have been the most widely studied to date. Levy and colleagues and Heazell and colleagues showed an increase of p53 and of the cascade pro-apoptotic proteins in IUGR pregnancies compared to controls (Levy et al. 2002; Heazell et al. 2011). Contrary to these findings, Jeschke and colleagues evinced a reduced expression of p53 in cases of IUGR in relation to controls (Jeschke et al. 2006), while Endo and colleagues found no difference in the expression of p53 between cases and controls (Endo et al. 2005). From our analysis, it appears that p53 immunohistochemical expression was not significantly affected by gestational age among controls (although when including cases, it was significantly increased as gestational age increased), and our results confirm that p53 was increased in IUGR compared to controls in both groups of pathology between 22- and 34-week gestation and above 34-week gestation. Focusing on this more deeply, in the range between 22- and 34-week gestation, p53 was increased in all obstetric pathologies likely to be of placental origin, while in the over 34-week gestation p53 was over-expressed only in the placentas of pregnancies complicated by IUGR, in comparison both with controls and with late PE. It is also noteworthy that Jeschke and colleagues did not find differences between PE and controls, but did for HELLP compared with controls, where p53 was significantly increased in HELLP pregnancies (Jeschke et al. 2006). In our study, we confirm a significant increase of p53 immunohistochemical expression in placentas from pregnancies affected by HELLP, but in addition to this, we observed the same significant difference for PE.

We are aware of only one study that addresses the expression of p21 in the trophoblast of placentas from IUGR pregnancies. This study provides a comparison between six placentas from normal pregnancies with a 39 -week term and six placentas from IUGR pregnancies with a median of 37-week gestation (Heazell et al. 2011). Here, Heazell and colleagues found an increased expression of p21 in IUGR when compared to controls (Heazell et al. 2011). Our own results support these findings, indicating an increased expression of p21 in IUGR (and incidentally also in SGA pregnancies) compared to controls for patients who delivered after 34-week gestation. However, this difference did not hold for the range of cases, including IUGR, who delivered between 22- and 34-week gestation. This could be due to the fact that early and late IUGR are two different pathologies or simply to the fact that p21 is subject to fluctuations over the course of a pregnancy, playing one function in cases where IUGR fetuses are delivered before or after 34-week gestation, and another, general role in early placental life.
There is likewise not a great deal of the existing literature concerning 8-OHdG and APE1. In the one study we were able to locate, an evaluation of the expression level of these two proteins in the trophoblast of pathological pregnancies is presented. Here, 11 placentas from full-term pregnancies are compared with 10 placentas from pregnancies affected by late-onset preeclampsia and 13 placentas from pregnancies affected predominantly by early onset preeclampsia associated with IUGR (Fujimaki et al. 2011). In this context, Fujimaki and colleagues found that 8-OHdG expression levels are higher in both the categories of pathological pregnancies but its expression is particularly pronounced among cases of IUGR (mainly before 34-week gestation) (Fujimaki et al. 2011). We correspondingly found a higher expression of 8-OHdG in IUGR cases, as well as in our other pathologic groups, where delivery was between 22- and 34-week gestation, as compared with controls. However, comparing IUGR pregnancies with PE or HELLP pregnancies, a significantly increased expression of 8-OHdG was only observed locally in the cytoplasm. With regard to APE1, Fujimaki and colleagues found a higher expression of APE1 in placentas from preeclamptic pregnancies than in both controls and in PE associated with IUGR (Fujimaki et al. 2011). In our study, we too observed a significant association between APE1 and hypertensive pregnancy disorders. Our finding noted above concerning a cytoplasmic staining for 8-OHdG could be explained by the localization of 8-OHdG on RNA sites (Tell et al. 2010). In a similar vein, we noted cytoplasmic APE1 staining in our results. Since APE1 is known to be localized in mitochondria (Barchiesi et al. 2015), the higher levels of specifically cytoplasmic APE1 in pathologic pregnancies (especially $\mathrm{PE})$ as compared with controls is potentially related to the fact that in PE both mitochondria and mitochondrial proteins are more abundant (Jones and Fox 1980; Wang and Walsh 1998).

In PE and IUGR pregnancies, both IL-6 and IL-8 have been found at increased levels in maternal and fetal fluids (Hahn-Zoric et al. 2002; Sargent et al. 2006; Visentin et al. 2014). A previous study went on to demonstrate that mRNA levels of IL-6 and IL-8 in placental tissue were found to be increased in IUGR/SGA pregnancies when compared with controls (Hahn-Zoric et al. 2002). In contrast to these data, a recent study concluded that there were no significant differences in IL-6 or IL-8 mRNA placental tissue levels between IUGR and controls (Amu et al. 2006). In our study, we generally found IL-6 placental immunohistochemical scores to be higher in cases than in controls, and IL- 8 scores to be significantly lower.

In this study we hypothesized that placenta from pregnancy complications (e.g., PE or IUGR) has an increased aging velocity in comparison with controls. Indeed our results do show that immunohistochemistry scores of 
aging biomarkers are generally higher in cases than in controls. In addition, increased APE1 levels may be of importance. Should future research confirm these findings, APE1 levels could be decreased by diet supplementations-perhaps to be targeted at high-risk pregnancies (e.g., Catechins isolated from the leaves of green tea associated with Curcumin) (Thakur et al. 2014). SASP may also exacerbate the effect of placental aging by establishing a vicious mechanism due to cytokines such IL-6. Thus, the suppression of SASP could also be a possible therapeutic target (Hayakawa et al. 2015). Furthermore, aspirin treatment could decrease trophoblast levels of p53 (Costa et al. 2013).

While this study is limited in terms of its retrospective design and restriction only to the immunohistochemical expression of the studied factors, it benefits from the wide range of pathology included in the tissue micro-array, which allowed us to assess several pathologies in a standardized manner. The immunohistochemical expression analysis alone is limiting the possibility of comparing the expression of two different proteins between them and further studies with quantitative techniques, even on small sample size, are needed to confirm our data. Moreover, by including controls stratified for gestational age, we have presented a set of data that are rare to find in other published studies. Despite our efforts, particularly in early placental pathology still exists a gestational age gap between cases and controls that was found to be irrelevant after multivariate logistic regression analysis.

In summary, we found that placentas from pathological pregnancies have an altered expression of $8-\mathrm{OHdG}, \mathrm{p} 53$, p21, APE1, IL-6, and IL-8. The alterations of intracellular pathways involving these elements can be the cause or the consequence of placental dysfunction in the various diseases considered. Further analysis of the role of p53, p21, APE1, IL-6, and IL-8 in the field of obstetric pathology is needed to understand whether a targeted therapy to their rebalancing may have clinical significance.

\begin{abstract}
Acknowledgments We are grateful to Eilidh PJ McIntosh for her suggestions on the style and composition of our English. We are grateful to Vito D'Aietti for his precious help. We are grateful to Matteo De Luca for the technical assistance in realizing TMA and Marta Forgiarini and Magdalena Marciniak for technical support. We are also grateful to Prof. Diego Marchesoni, Prof. Carlo Alberto Beltrami, Prof. Carla Di Loreto, Prof. Dr. med. Walter Klockenbusch, and Prof. Gabriele Köhler for their help and suggestions. Furthermore, this research is based on the Ph.D. dissertation of Dr Ambrogio P Londero that took place in the University of Udine.
\end{abstract}

Authors' contribution APL, MO, TG, SM, AF, SB, NN, ES, and LM made substantial contributions to conception and design or acquisition of data or to analysis and interpretation of data. APL, MO, AC, $\mathrm{SM}, \mathrm{AF}, \mathrm{SB}, \mathrm{NN}, \mathrm{LD}, \mathrm{GT}, \mathrm{RJL}$, and LM were involved in drafting the article or revising it critically for important intellectual content. All authors read and approved the final manuscript.

\section{Compliance with ethical standards}

Conflict of interests The authors declare that they have no potential conflicts of interest relevant to this article. This study had no financial support.

\section{References}

Amu S, Hahn-Zoric M, Malik A, Ashraf R, Zaman S, Kjellmer I, Hagberg H, Padyukov L, Hanson LA (2006) Cytokines in the placenta of Pakistani newborns with and without intrauterine growth retardation. Pediatr Res 59:254-258. doi:10.1203/01. pdr.0000196332.37565.7d

Barchiesi A, Wasilewski M, Chacinska A, Tell G, Vascotto C (2015) Mitochondrial translocation of ape1 relies on the mia pathway. Nucleic Acids Res 43:5451-5464. doi:10.1093/nar/gkv433

Baxter JK, Weinstein L (2004) Hellp syndrome: the state of the art. Obstet Gynecol Surv 59:838-845

Biron-Shental T, Sukenik-Halevy R, Sharon Y, Goldberg-Bittman L, Kidron D, Fejgin MD, Amiel A (2010) Short telomeres may play a role in placental dysfunction in preeclampsia and intrauterine growth restriction. Am J Obstet Gynecol 202:381.e1-387.e7. doi:10.1016/j.ajog.2010.01.036

Brown MA, Lindheimer MD, de Swiet M, Van Assche A, Moutquin JM (2001) The classification and diagnosis of the hypertensive disorders of pregnancy: statement from the international society for the study of hypertension in pregnancy (isshp). Hypertens Pregnancy 20:IX-XIV. doi:10.1081/PRG-100104165

Burton DGA, Krizhanovsky V (2014) Physiological and pathological consequences of cellular senescence. Cell Mol Life Sci 71:43734386. doi:10.1007/s00018-014-1691-3

Cesaratto L, Codarin E, Vascotto C, Leonardi A, Kelley MR, Tiribelli C, Tell G (2013) Specific inhibition of the redox activity of ape1/ ref- 1 by e 3330 blocks tnf- $\alpha$-induced activation of il- 8 production in liver cancer cell lines. PLoS One 8:e70909. doi:10.1371/journal.pone.0070909

Coppé JP, Patil CK, Rodier F, Sun Y, Muñoz DP, Goldstein J, Nelson PS, Desprez PY, Campisi J (2008) Senescence-associated secretory phenotypes reveal cell-nonautonomous functions of oncogenic ras and the p53 tumor suppressor. PLoS Biol 6:2853-2868. doi:10.1371/journal.pbio.0060301

Costa F, Panagodage S, Brennecke S, Murthi P (2013) Oc03.01: low-dose aspirin improves trophoblastic function in early-onset pre-eclampsia. Ultrasound Obstet Gynecol 42:5. doi:10.1002/ uog. 12591

Davy P, Nagata M, Bullard P, Fogelson NS, Allsopp R (2009) Fetal growth restriction is associated with accelerated telomere shortening and increased expression of cell senescence markers in the placenta. Placenta 30:539-542. doi:10.1016/j.placenta.2009.03.005

Endo H, Okamoto A, Yamada K, Nikaido T, Tanaka T (2005) Frequent apoptosis in placental villi from pregnancies complicated with intrauterine growth restriction and without maternal symptoms. Int J Mol Med 16:79-84

Ewen ME, Miller SJ (1996) p53 and translational control. Biochim Biophys Acta 1242:181-184

Fruscalzo A, Schmitz R, Klockenbusch W, Köhler G, Londero AP, Siwetz M, Huppertz B (2012) Human placental transthyretin in fetal growth restriction in combination with preeclampsia and the hellp syndrome. Histochem Cell Biol 138:925-932. doi:10.1007/ s00418-012-0997-1

Fujimaki A, Watanabe K, Mori T, Kimura C, Shinohara K, Wakatsuki A (2011) Placental oxidative dna damage and its repair in preeclamptic women with fetal growth restriction. Placenta 32:367372. doi:10.1016/j.placenta.2011.02.004 
Ginsberg D, Mechta F, Yaniv M, Oren M (1991) Wild-type p53 can down-modulate the activity of various promoters. Proc Natl Acad Sci USA 88:9979-9983

Hahn-Zoric M, Hagberg H, Kjellmer I, Ellis J, Wennergren M, Hanson LA (2002) Aberrations in placental cytokine mrna related to intrauterine growth retardation. Pediatr Res 51:201-206. doi:10.1203/00006450-200202000-00013

Hayakawa T, Iwai M, Aoki S, Takimoto K, Maruyama M, Maruyama W, Motoyama N (2015) Sirt1 suppresses the senescence-associated secretory phenotype through epigenetic gene regulation. PLoS One 10:e0116480. doi:10.1371/journal.pone.0116480

Heazell AEP, Lacey HA, Jones CJP, Huppertz B, Baker PN, Crocker IP (2008) Effects of oxygen on cell turnover and expression of regulators of apoptosis in human placental trophoblast. Placenta 29:175-186. doi:10.1016/j.placenta.2007.11.002

Heazell AEP, Sharp AN, Baker PN, Crocker IP (2011) Intra-uterine growth restriction is associated with increased apoptosis and altered expression of proteins in the p53 pathway in villous trophoblast. Apoptosis 16:135-144. doi:10.1007/ s10495-010-0551-3

Izutsu T, Kudo T, Sato T, Nishiya I, Ohyashiki K, Mori M, Nakagawara K (1998) Telomerase activity in human chorionic villi and placenta determined by trap and in situ trap assay. Placenta 19:613-618

Jeschke U, Schiessl B, Mylonas I, Kunze S, Kuhn C, Schulze S, Friese K, Mayr D (2006) Expression of the proliferation marker ki-67 and of p53 tumor protein in trophoblastic tissue of preeclamptic, hellp, and intrauterine growth-restricted pregnancies. Int J Gynecol Pathol 25:354-360. doi:10.1097/01.pgp.0000225838.29127.6

Jones CJ, Fox H (1980) An ultrastructural and ultrahistochemical study of the human placenta in maternal pre-eclampsia. Placenta $1: 61-76$

Ju Z, Choudhury AR, Rudolph KL (2007) A dual role of p21 in stem cell aging. Ann NYAcad Sci 1100:333-344. doi:10.1196/ annals. 1395.036

Kimura C, Watanabe K, Iwasaki A, Mori T, Matsushita H, Shinohara K, Wakatsuki A (2013) The severity of hypoxic changes and oxidative dna damage in the placenta of early-onset preeclamptic women and fetal growth restriction. J Matern Fetal Neonatal Med 26:491-496. doi:10.3109/14767058.2012.733766

Kudo T, Izutsu T, Sato T (2000) Telomerase activity and apoptosis as indicators of ageing in placenta with and without intrauterine growth retardation. Placenta 21:493-500. doi:10.1053/ plac. 2000.0538

Levy R, Smith SD, Yusuf K, Huettner PC, Kraus FT, Sadovsky Y, Nelson DM (2002) Trophoblast apoptosis from pregnancies complicated by fetal growth restriction is associated with enhanced p53 expression. Am J Obstet Gynecol 186:1056-1061

Ljungman M (2000) Dial 9-1-1 for p53: mechanisms of p53 activation by cellular stress. Neoplasia 2:208-225

Lombard DB, Chua KF, Mostoslavsky R, Franco S, Gostissa M, Alt FW (2005) Dna repair, genome stability, and aging. Cell 120:497-512. doi:10.1016/j.cell.2005.01.028

Londero AP, Bertozzi S, Visentin S, Fruscalzo A, Driul L, Marchesoni D (2013) High placental index and poor pregnancy outcomes: a retrospective study of 18386 pregnancies. Gynecol Endocrinol 29:666-669. doi:10.3109/09513590.2013.798273

Madlener S, Ströbel T, Vose S, Saydam O, Price BD, Demple B, Saydam N (2013) Essential role for mammalian apurinic/apyrimidinic (ap) endonuclease ape1/ref-1 in telomere maintenance. Proc Natl Acad Sci USA 110:17844-17849. doi:10.1073/ pnas. 1304784110
Miyashita T, Kitada S, Krajewski S, Horne WA, Delia D, Reed JC (1995) Overexpression of the bcl-2 protein increases the half-life of p21bax. J Biol Chem 270:26049-26052

Reed M, Woelker B, Wang P, Wang Y, Anderson ME, Tegtmeyer P (1995) The c-terminal domain of p53 recognizes dna damaged by ionizing radiation. Proc Natl Acad Sci USA 92:9455-9459

Rossé T, Olivier R, Monney L, Rager M, Conus S, Fellay I, Jansen B, Borner C (1998) Bcl-2 prolongs cell survival after baxinduced release of cytochrome c. Nature 391:496-499. doi: $10.1038 / 35160$

Rossi DJ, Jamieson CHM, Weissman IL (2008) Stems cells and the pathways to aging and cancer. Cell 132:681-696. doi:10.1016/j. cell.2008.01.036

Rossi A, Bortolotti N, Vescovo S, Romanello I, Forzano L, Londero AP, Ambrosini G, Marchesoni D, Curcio F (2013) Ischemiamodified albumin in pregnancy. Eur J Obstet Gynecol Reprod Biol. doi:10.1016/j.ejogrb.2013.06.037

Sargent IL, Borzychowski AM, Redman CWG (2006) Nk cells and human pregnancy-an inflammatory view. Trends Immunol 27:399-404. doi:10.1016/j.it.2006.06.009

Takagi Y, Nikaido T, Toki T, Kita N, Kanai M, Ashida T, Ohira S, Konishi I (2004) Levels of oxidative stress and redox-related molecules in the placenta in preeclampsia and fetal growth restriction. Virchows Arch 444:49-55. doi:10.1007/s00428-003-0903-2

Tamura D, Merideth M, DiGiovanna JJ, Zhou X, Tucker MA, Goldstein AM, Brooks BP, Khan SG, Oh KS, Ueda T, Boyle J, Moslehi R, Kraemer KH (2011) High-risk pregnancy and neonatal complications in the dna repair and transcription disorder trichothiodystrophy: report of 27 affected pregnancies. Prenat Diagn 31:1046-1053. doi:10.1002/pd.2829

Tell G, Damante G, Caldwell D, Kelley MR (2005) The intracellular localization of ape1/ref-1: more than a passive phenomenon? Antioxid Redox Signal 7:367-384. doi:10.1089/ars.2005.7.367

Tell G, Wilson DM 3rd, Lee CH (2010) Intrusion of a dna repair protein in the rnome world: is this the beginning of a new era? Mol Cell Biol 30:366-371. doi:10.1128/MCB.01174-09

Thakur S, Sarkar B, Cholia RP, Gautam N, Dhiman M, Mantha AK (2014) Ape1/ref-1 as an emerging therapeutic target for various human diseases: phytochemical modulation of its functions. Exp Mol Med 46:e106. doi:10.1038/emm.2014.42

Thakur S, Dhiman M, Tell G, Mantha AK (2015) A review on proteinprotein interaction network of ape1/ref-1 and its associated biological functions. Cell Biochem Funct 33:101-112. doi:10.1002/ cbf. 3100

Vascotto C, Salzano AM, D'Ambrosio C, Fruscalzo A, Marchesoni D, di Loreto C, Scaloni A, Tell G, Quadrifoglio F (2007) Oxidized transthyretin in amniotic fluid as an early marker of preeclampsia. J Proteome Res 6:160-170. doi:10.1021/pr060315z

Vascotto C, Fantini D, Romanello M, Cesaratto L, Deganuto M, Leonardi A, Radicella JP, Kelley MR, D'Ambrosio C, Scaloni A, Quadrifoglio F, Tell G (2009) Ape1/ref-1 interacts with npm1 within nucleoli and plays a role in the rrna quality control process. Mol Cell Biol 29:1834-1854. doi:10.1128/MCB.01337-08

Visentin S, Lapolla A, Londero AP, Cosma C, Dalfrà M, Camerin M, Faggian D, Plebani M, Cosmi E (2014) Adiponectin levels are reduced while markers of systemic inflammation and aortic remodelling are increased in intrauterine growth restricted mother-child couple. Biomed Res Int. doi:10.1155/2014/401595

Wang Y, Walsh SW (1998) Placental mitochondria as a source of oxidative stress in pre-eclampsia. Placenta 19:581-586

Young ARJ, Narita M (2009) Sasp reflects senescence. EMBO Rep 10:228-230. doi:10.1038/embor.2009.22 